\title{
Effect of Mo Content on the Microstructure and Mechanical Properties of Tic Steel Bonded Carbide
}

 \\ ${ }^{1}$ State Key Laboratory of Powder Metallurgy, Central South University, Changsha 410083, China \\ ${ }^{2}$ Key Laboratory of Powder Metallurgy in Advanced Manufacturing of Laiwu, Laiwu Vocational and \\ Technical College; Laiwu 271100, China \\ aguopingli@csu.edu.cn, ' Izy6268361@163.com, 'sunlihui0114@126.com,

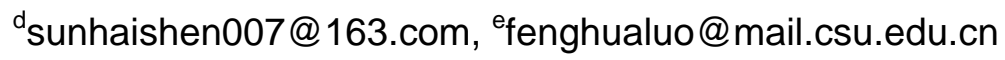 \\ *Corresponding author: guopingli@csu.edu.cn
}

Keywords TiC; Steel bonded carbide; Mo content; Microstructure, Mechanical properties.

\begin{abstract}
The effect of Mo content on microstructure and mechanical properties of TiC steel bonded carbide was investigated when Mo content was $0.6 \%, 1.25 \%, 2 \%$ and $2.5 \%$ respectively. Results showed that density, hardness and transverse rupture strength of the sintered material achieved the best combined values when Mo content was $1.25 \%$. At this point, the sintered density reached $98.56 \%$ theoretical density, the hardness is $64.2 \mathrm{HRC}$, and the transverse rupture strength in sintering and heat treatment states was $1532 \mathrm{MPa}$ and 2274MPa respectively. When Mo content is more than $1.25 \%$, grains of the hard phase grew up clearly and brittleness of the sintering material increased because of the bigger thickness of $(\mathrm{Ti}, \mathrm{Mo}) \mathrm{C}$ solid solution layer generated on the surface of $\mathrm{TiC}$ phase, resulting in severe deterioration of mechanical properties of the sintered material.
\end{abstract}

\section{Introduction}

Steel bonded carbide, fabricated by powder metallurgy method, is a kind of material used steel as binder and refractory metal carbides (WC, TiC) as hard phase ${ }^{[1]}$. Carbide phase gives the hard alloy good abrasion resistance and heat resistance and steel binder phase provides it with excellent properties of heat treatment, machinability, forgeability, weldability etc. Therefore, the steel bonded carbide is a kind of new engineering material between alloy steel and cemented carbide ${ }^{[2-4]}$. Compared with the hard phase WC, the advantages of TiC are of high hardness, anti-oxidation, corrosion resistance, low density, and good thermal stability. Meanwhile the grain growth tendency of $\mathrm{TiC}$ is smaller than that of WC in sintering process, which provides the hard alloy with excellent properties and wide use in cutting tools, moulds, wear-resisting components etc ${ }^{[5,6]}$.

However, the wettability of TiC hard phase and binder phase is poor, leading to low density and high porosity of the sintered material which affected its mechanical properties and operational performance seriously. So it is necessary to add some elements to improve the wettability of TiC and binder phase. Mo is a metal used effectively and widely in research and production of the cemented carbides (especially cobalt-free cemented carbides), steel bonded carbides, metal/ceramic applications ${ }^{[7,8]}$. The mechanism of improving wettability of the hard phase and binder metal lied in the interface reaction between the hard phase and the additive metal, so solid solution and compounds were generated with metal/ceramic characteristic ${ }^{[9-11]}$. At present, with the development of computational materials science, the study of material has become deeply and gone into the electronic theory through atomic theory which can explain the nature of the wettability at valence electron structure level ${ }^{[12-14]}$. Xu etc ${ }^{[15]}$ investigated the influence of various carbides on the number of covalent bonding electron of $\mathrm{TiC}$ and results showed that adding carbide could make the number of covalent bonding electron and bond energy increase which decreased the wetting angle of system and improved the wettability of material system. Xu etc ${ }^{[16]}$ added Mo into the system of TiC/Fe steel bonded carbide and researched the influence of Mo on the valence electron structure of 
(Ti,Mo)C solid solution and interface valence electron structure of TiC/Fe. Results showed that adding Mo could make the strongest covalent bonds of ceramic enhancing and the surface energy improving, which is good for metal to the wetting of ceramic phase. The (Ti,Mo)C solid solution was generated on surface of the TiC particles, enhancing the interfacial chemical bonding force, increasing interface binding and improving the wettability. Generally speaking, the additive Mo could generate a layer of $(\mathrm{Ti}, \mathrm{Mo}) \mathrm{C}$ solid solution on the surface of $\mathrm{TiC}$ phase which had stronger metallicity and better affinity to iron base binder and improved the wettability between the hard phase and the binder ${ }^{[17,18]}$. In this paper, effect of Mo content on microstructure and mechanical properties of TiC high manganese steel bonded carbide was investigated.

\section{Experimental Procedure}

TiC powder is produced by Zhuzhou Anglixi technology Co. Ltd. The average size of TiC is $3.3 \mu \mathrm{m}$, and the chemical composition is shown in Table 1. The formula of high manganese steel bonded carbide is shown in table 2 . The main point is the guarantee of carbon/manganese ratio of binder system, which is $1:(10 \sim 14)$. Carbon content can be increased properly according to the oxygen content of the milled powder. The size of other powders is $6 \sim 10 \mu \mathrm{m}$. The materials are weighed according to the formula in Table 2. The amount of Mo is $0.6 \%, 1.25 \%, 2 \%, 2.5 \%$ respectively. After premixing, powders are poured into ball mill for wet grinding in alcohol for $24 \mathrm{~h}$. The ratio of ball/material is 5:1. Then the required samples are obtained after mixing glue, granulation, forming, sintering, heat treatment process etc. The density, hardness, transverse rupture strength, impact toughness of the sintered material are measured and the porosity, microstructure, fracture morphology are also observed.

Table 1 Nominal composition (in wt \%) of TiC powder in the present experiment

\begin{tabular}{lcccccc}
\hline Powder & Ti & total C & dissociative C & O & N & Fe \\
\hline TiC & Bal. & 19.32 & 0.12 & 0.20 & 0.18 & 0.25 \\
\hline
\end{tabular}

Table 2 Formulation design of the samples in the experiment (in wt \%)

\begin{tabular}{llllccc}
\hline $\mathrm{TiC}$ & $\mathrm{Ni}$ & $\mathrm{Mo}$ & $\mathrm{Mn}$ & $\mathrm{C}$ & $\mathrm{Cu}$ & $\mathrm{Fe}$ \\
\hline $50 \%$ & 2.58 & 0.6 & 8.45 & 0.65 & 0.08 & Bal. \\
$50 \%$ & 2.58 & 1.25 & 8.45 & 0.65 & 0.08 & Bal. \\
$50 \%$ & 2.58 & 2 & 8.45 & 0.65 & 0.08 & Bal \\
$50 \%$ & 2.58 & 2.5 & 8.45 & 0.65 & 0.08 & Bal \\
\hline
\end{tabular}

\section{Results and Discussion}

\section{Density}

The density of sintered materials is measured with Archimedes method, as shown in Table 3. As seen from Table 3, the highest density is the sample with $1.25 \%$ Mo content which is $98.56 \%$ theoretical density, meanwhile the lowest density is the sample with $0.6 \%$ Mo content. With the increase of Mo content, the density does not increase all along. Compared with the sample with Mo content $1.25 \%$, the density of samples with Mo content $2 \%$ and $2.5 \%$ becomes lower. Fig 1 is the effect of Mo content on porosity of the sintering material which can reflect the density of the sintered material visually. It can be seen from Figure 1, porosity of the sample with Mo content $1.25 \%$ is the least and density is highest. Porosity of the sample with Mo content $0.6 \%$ is the most, and density is lowest, which is consistent with the density test results. When Mo content is small, the Mo containing layer is not formed completely on hard phase surface, resulting in poor wettability. Meanwhile porosity of the sintering material increases and density is low. With the increase of Mo content, a (Ti,Mo)C solid solution layer is formed completely on hard phase surface in sintering, improving the wettability between the hard phase and the binder, leading to lower 
porosity and higher density of the material. The reason why the porosity of the sintering material increase with further increase of Mo content is that the thickness of (Ti,Mo)C solid solution layer on the hard phase surface increases. The dissolve-precipitation process becomes swift and fiercely and some particles of hard phase grew up too much and quickly, so sintering power reduced sharply, the porosity increases and the density becomes lower. In fact, the sintering densification mechanism is not different and the main question is the change of sintering kinetics.

Table 3 Effect of Mo content on density of the sintered samples

\begin{tabular}{lccc}
\hline Mo content (\%) Theoretical density $\left(\mathrm{g} / \mathrm{cm}^{3}\right)$ & Sintered density $\left(\mathrm{g} / \mathrm{cm}^{3}\right)$ & Relative density $(\%)$ \\
\hline 0.6 & 6.359 & 6.176 & 97.12 \\
1.25 & 6.374 & 6.280 & 98.56 \\
2 & 6.392 & 6.262 & 97.97 \\
2.5 & 6.403 & 6.255 & 97.69 \\
\hline
\end{tabular}
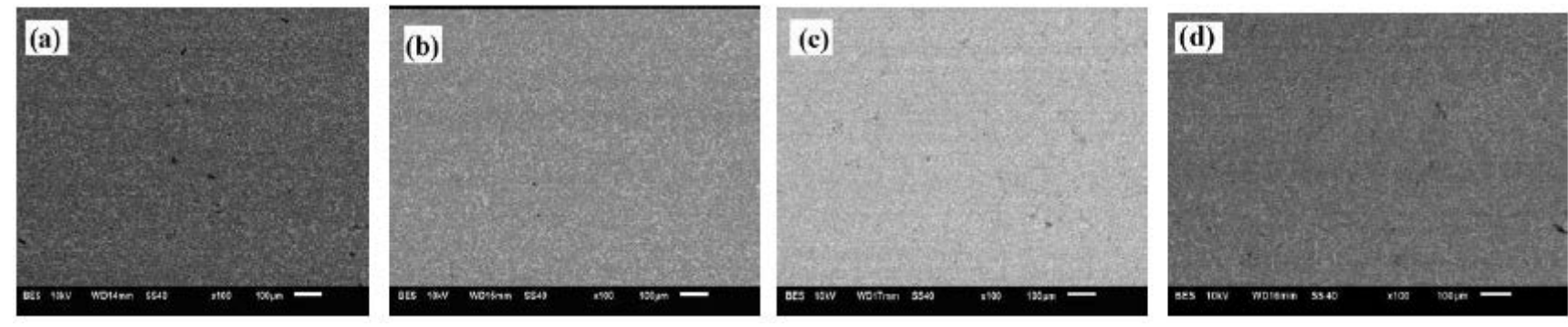

Figure 1 Effect of Mo content on porosity of sintered samples in the experiment, and Mo content is (a) $0.6 \%$, (b) $1.25 \%$, (c) $2 \%$, (d) $2.5 \%$ respectively.

\section{Hardness}

Hardness of the sintered samples is tested with HR150-B Rockwell hardness tester. It can be confirmed the hardness value increases with the increase of Mo content in Figure 2. When Mo content is $2 \%$, the hardness reaches the maximum value. Hardness of the samples with Mo content $1.25 \%$ and $2 \%$ is nearly similar, which is HRC64.2 and HRC64.5 respectively. Hardness of the sample reduces when Mo content is $2.5 \%$. Thus, according to the relationship between the strength and hardness, it can be guessed the strength and toughness of the samples are lower ${ }^{[19-21]}$. Therefore it can be preliminary thought that the optimal Mo content should be between $1.25 \%$ and $2 \%$ according to the hardness of the sintered material. The sintered samples are heated to $1050 \sim 1100^{\circ} \mathrm{C}$ and then quenched, so the matrix changes into austenite. Although the hardness of austenite is low, there is little fluctuation on macro hardness due to the high content and big volume fraction of the hard phase.

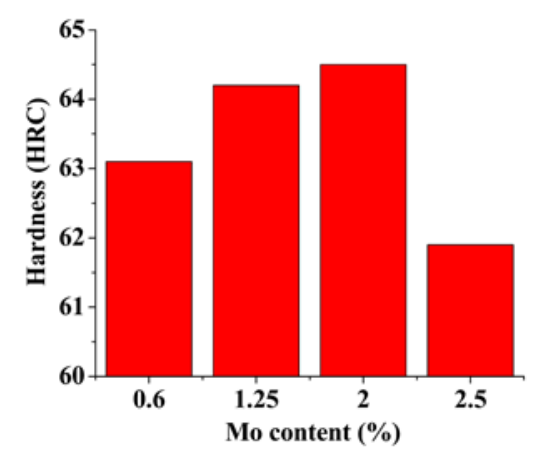

Figure 2 Effect of Mo content on hardness of sintered samples in the experiment 


\section{The Microstructure}

Figure 3 is the metallographic images of the sintered material. The gray areas are $\mathrm{TiC}$ and bright areas are binder in the image. It can be seen when the Mo content is $0.6 \%$ (a) and $2.5 \%$ (d), growth tendency of the grain is serious, meanwhile there are crystal grains growing up abnormally in the figure. When Mo content is $1.25 \%$ (b) and $2 \%$ (c), growth tendency of the abnormal grain is smaller, and there are no abnormally large hard phase particles. Although particles in image (c) are relatively small, the distribution of hard phase is inhomogeneous and the "bridge" phenomenon is serious to a certain extent. Actually this is another form of growing up of the grain. During application, the binder between "bridge" grains is less and the bond strength is lower, so it is easy to crack between particles and lead to drop of the hard phase and failure of the sintered material. Although grains of the hard phase grow up to some extent in image (b), the distribution of the hard phase is uniform in the experimental samples. Therefore, the sintered material with Mo content $1.25 \%$ has ideal microstructure.


Figure 3 Effect of Mo content on microstructure of sintered samples in the experiment, and Mo content is (a) $0.6 \%$, (b) $1.25 \%$, (c) $2 \%$, (d) $2.5 \%$ respectively.

Previous researches $[1,11,17]$ show that Mo is mainly distributed on the hard phase surface, forming a core-ring structure in the alloy. Main phase in the core-ring structure is (Ti,Mo)C solid solution, and the Mo content in adhesives is very few. In this paper the Mo distribution is also tested and the result is consistent with previous researches. Studies have shown that the thickness of (Ti,Mo)C solid solution layer on the hard phase surface is about $0.5 \mu \mathrm{m}$. However, the brittleness increases with the increase of the thickness of (Ti,Mo)C solid solution layer, and affects strength and toughness greatly of the material. In fact, the process as mixing, ball milling etc can not guarantee the uniformity of Mo in the alloy absolutely, therefore the thickness of (Ti,Mo)C solid solution layer on the hard phase surface is not uniform of the sintered material. As for the exact thickness of the solid solution layer, it is difficult to confirm. However, through the inspection and analysis on properties of the sintering material, especially on the transverse rupture strength and impact toughness, we can indirectly confirm Mo content as the wetting agent and the thickness of solid solution layer on the hard phase surface. When Mo content reaches a certain value, the reduction of these indexes can reflect the heterogeneous distribution of Mo element and the thickness of (Ti,Mo)C solid solution layer, thus resulting in a loss of material performance.

Figure 4 is the test results for Mo distribution of a big crystalline grain of the sample with Mo content $2 \%$. The measuring position is in the center of the grain in the image. In this point, the content of Mo element is high, illustrating that the thickness of (Ti,Mo)C solid solution on the surface of the grain is very big, so it is a big brittle particle. If the image is further enlarged, the color of solid solution layer is lighter than that of the pure hard phase. This kind of grain will crack and fall off easily under impact load, leading to wear and failure of the material. When Mo content is higher, this kind of grain must be existed all along. Therefore when Mo content is appropriate and the size of Mo powder is very small, it is uniformly distributed in the alloy and a thin (Ti,Mo)C solid solution layer will be formed on every grain surface of the hard phase. This can improve wettability of the hard phase and the binder, and not increase the brittleness of the material, guaranteeing the performance of the sintered alloy. 

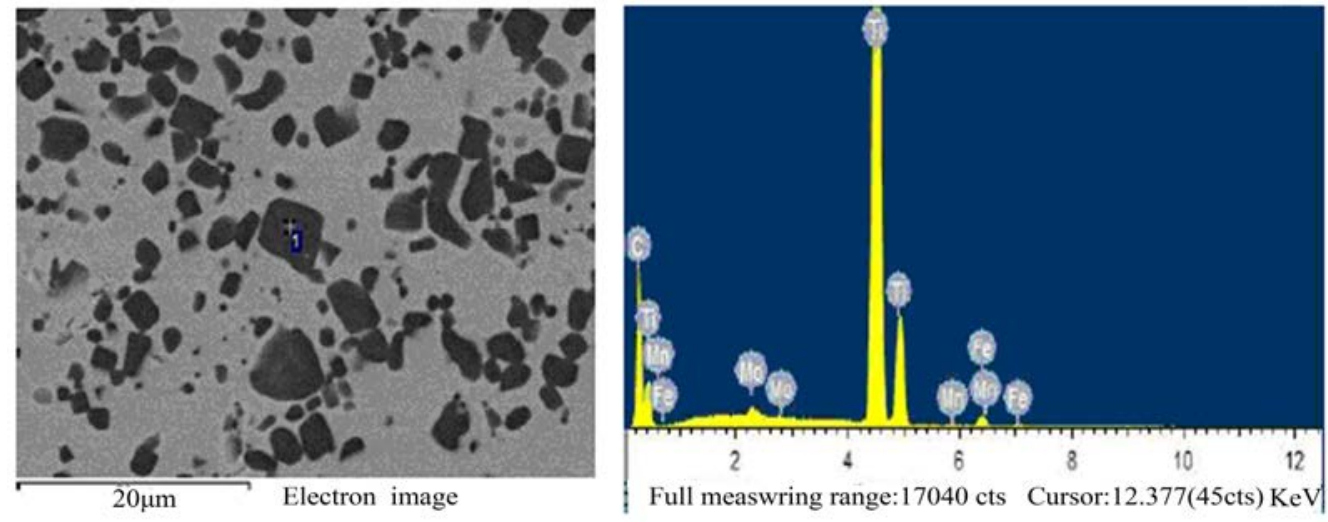

\begin{tabular}{ccccccc}
\hline Element & C K & Ti K & Mn K & Fe K & Mo L & Total weight \\
\hline Weight percentage & 26.40 & 70.81 & 0.21 & 1.67 & 0.91 & 100.00 \\
Atomic percentage & 59.10 & 39.74 & 0.10 & 0.80 & 0.26 & 100.00 \\
\hline
\end{tabular}

Figure 4 Test for Mo distribution of a big crystalline grain of the sample with Mo content $2 \%$

There are two methods of Mo element to add in the alloy, one is added in the form of pure element, the other is in the form of $\mathrm{Mo}_{2} \mathrm{C}$, which one is better still needs further study. Considering the homogeneity of Mo distribution on the surface of every hard phase particle, maybe it is the third and the best choice of the addition with Fe/Mo pre-alloyed powder. In sintering process of the cemented carbides, Mo and $\mathrm{C}$ reacted to form $\mathrm{Mo}_{2} \mathrm{C}$ phase firstly before $900^{\circ} \mathrm{C}^{[22]}$. Subsequently $\mathrm{Mo}_{2} \mathrm{C}$ dissolved in the binder and hindered the growth of hard phase grains, and the inhibiting effect was the best when inhibitor content exceeded its saturated concentration in liquid binder ${ }^{[23]}$. In this study, $\mathrm{Mo}_{2} \mathrm{C}$ did not reach the saturated concentration in liquid binder because the Mo content was few and the quantity of liquid phase was much more, so the inhibiting effect of TiC growth was not effective. However, excessive Mo addition can increase the brittleness and be deleterious to the mechanical properties of the sintered material. So it is not appropriate to add excessive inhibitor to hinder the growth of hard phase in the production for high strengthen and high toughness of the steel bonded carbides, other methods should be taken into account.

\section{Transverse Rupture Strength, Impact Toughness and Observation of the Fracture}

The samples are machining for test of transverse rupture strength and impact toughness according to the national standards. The basic size of samples for test of the transverse rupture strength is $5 \times 5 \times 35 \mathrm{~mm}^{3}$, and the basic size of samples for test of the impact toughness is $10 \times 10 \times 55 \mathrm{~mm}^{3}$. After grinding and polishing, the surface roughness of the machined samples meets the standard requirements. Figure 5 is transverse rupture strength of the sintered material. It can be seen that when Mo content increased from $0.6 \%$ to $1.25 \%$, the transverse rupture strength of samples in sintered and heat treatment state both reach the peak, $1532 \mathrm{MPa}$ and $2274 \mathrm{MPa}$ respectively. Then with the increase of Mo content, the transverse rupture strength decreases. When Mo content is $2.5 \%$, the transverse rupture strength of samples in sintered and heat treatment state falls to $1325 \mathrm{MPa}$ and 1897MPa, respectively. Figure 6 is the impact toughness of the sintered material. When Mo content is $1.25 \%$, impact toughness reaches maximum $12.78 \mathrm{~J} / \mathrm{cm}^{2}$. 


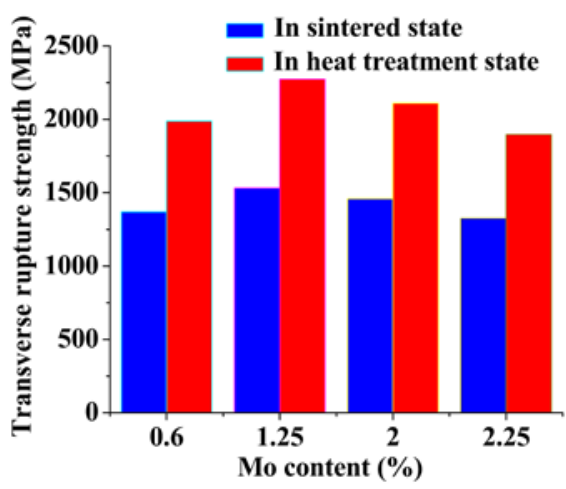

Figure 5 Effect of Mo content on bending strength of sintered samples in the experiment



Figure 6 Effect of Mo content on impact toughness of the samples (in heat treatment state)

It can be confirmed from the above data, when Mo content is $1.25 \%$, the transverse rupture strength and impact toughness of the sintered material are much better than that of TM52 whose transverse rupture strength and impact toughness are1900 2100MP and 9 11J/cm ${ }^{2}$ respectively, which could be increased $13.7 \%$ and $27.4 \%$, respectively.

Figure 7 is fracture morphology of the sintered material. The impact fracture of four groups of sample is combination of brittle fracture and ductile fracture. When Mo content is $1.25 \%$ (b), tear ridge caused by plastic fracture is obvious and homogeneous, whose area is relatively larger and the toughness is better. When Mo content is $0.6 \%$ (a), $2 \%$ (c), $2.5 \%$ (d), a certain amount of bulky cleavage or quasi cleavage plane appear in fracture, which belong to the brittle fracture typically and the area of brittle fracture is bigger than that in figure (b). When Mo content is $2 \%$ (c), the area of ductile fracture is concentrated, which is caused by the heterogeneity of its microstructure.


Figure 7 Fracture morphology of the samples in the experiment, and Mo content is (a) $0.6 \%$, (b) $1.25 \%$, (c) $2 \%$, (d) $2.5 \%$ respectively.

\section{Conclusions}

In sintering TiC high manganese steel bonded carbide, a certain amount of Mo was added to generate a $(\mathrm{Ti}, \mathrm{Mo}) \mathrm{C}$ solid solution layer on the hard phase surface and improve the wettability of 
the binder to hard phase and also enhance the performance of the sintering material. As for the density, hardness, transverse rupture strength and impact toughness of sintered materials, the combination of indexes achieves the best when Mo content is $1.25 \%$. The sintered density reaches 98.56\% theoretical density, the hardness is HRC64.2, and the transverse rupture strength in sintering and heat treatment state is $1532 \mathrm{MPa}$ and $2274 \mathrm{MPa}$ respectively. When Mo content increases, the thickness of $(\mathrm{Ti}, \mathrm{Mo}) \mathrm{C}$ solid solution layer on hard phase surface increases, leading to increase of the brittleness, and reducing performance of the material.

The components of steel bonded carbide are much more and affect each other and there is a lot of liquid phase quantity, so it is difficult to determine the optimal content of a particular element through the phase diagrams and materials calculation like cemented carbide. Therefore, in most cases, the optimal content of one element still should be determined by the experiment method according to the test of physics, dynamics and mechanical performance of the sintering material.

\section{Acknowledgements}

This work is supported by the 2014 Shandong technology development program (Nos. 2014GGA12044).

\section{References}

[1] Zhuzhou cemented carbide plant. Steel bonded carbide [M]. 1982, 1-4, Beijing.

[2] M. S. Li, The latest progress in foreign steel bonded carbide [J]. Journal of foreign metal materials, 1992, 5, 23-27.

[3] Z. Y. Chen, W. Chen, TiC cemented carbide [J]. Journal of cemented carbide, 2003, 20,197-199.

[4] Y. Zhang, X. Q. You, S. G. Tian, The development status of steel bonded carbide [J]. Journal of heat treatment, 2008, 23, 12-15.

[5] S. R. Liu, Strength of WC-Co cemented carbide [J], Cemented Carbide, 2002, 19, 129-135.

[6] C. Gutsfeld, Mechanically alloyed sintered steels with a high hard phase content, Metal Powder Report, 1990, 45, 769-771.

[7] M. H. Chen, N. Liu, Y. D. Xu, The research status of metal/ceramic wettability [J], Cemented Carbide, 2002, 19, 199-205.

[8] L. L. Wang, H. Y. Li, N. Liu, Influence of adding metal Mo on the microstructure and mechanical properties of WC-Co carbide [J], Rare metals and cemented carbide, 2010, 38, 31-35.

[9] F. Delannay, L. Froyen, A. Deruyttere, The wetting of solid by molten metals and its relation to preparation of metal-matrix compositions [J]. Material science, 1987, 22, 1-16.

[10] N. Eustthopoulos, Dynamics of wetting in reactive metal/ceramic systems, Acta Mater, 1998, 46, 2319-2327.

[11] K. Q. Liu, Q. Xu, H. J. Zhang, The preparation and application of metal ceramic [M], 2008, Beijing.

[12] J. W. Guo, Q. L. Liu, S. F. Rong, and The research status of department of TiC steel bonded carbide [J], Casting equipment and technology, 2010, 1, 48-54.

[13] H. R. Wang, Y. F. Ye, G. H. He, Property analysis of TiC valence electron structure [J], Science Bulletin, 2001, 46, 215-218.

[14] Q. X. Zhang, Performance study on the valence electron structure of $\mathrm{TiC}_{\mathrm{x}}$ solid solution, Journal of wuhan Technology University, 2000, 22, 5-7.

[15] Y. D. Xu, N. Liu, M. H. Chen, The wettability of ceramic phase in metal ceramic and its nature 
of the valence electron structure [J], Journal of hefei technology university, 2004, 27, 123-126.

[16] W. W. Xu, Z. G. Zou, Y. Wu, Theory analysis of valence electron on Mo improves wetting mechanism of TiC/Fe metal ceramic interfacial, Cemented Carbide, 2004, 24, 70-73.

[17] J. G. Yang, D. Q. Tan, Y. Chen, Cemented Carbide, 2012, Changsha.

[18] G. C. Guo, Powder metallurgy materials by liquid phase sintered [M], 2003, Beijing.

[19] D. L. Shu, Metal mechanical properties [M]. 1999, Beijing.

[20] H. F. Shi, X. Ren, Material mechanics performance [M]. 2010, Beijing.

[21] M. C. Sun, The mechanical properties of metal [M]. 2010, Harbin.

[22] N. Liu, Y. D. Xu, Z. H. Li, M. H. Chen, G. H. Li, L. D. Zhang. Influence of molybdenum addition on the microstructure and mechanical properties of TiC-based cermets with nano-TiN modification. Ceram Int 2003, 29(8), 919-925.

[23] N. Liu, C.H. Wu, Y. H. He, D. F. Zhang. Effect of Mo additions on the microstructure and properties of WC-TiC-Ni cemented carbides. Int. Journal of Refractory Metals and Hard Materials 2012, 30, 107-113. 
